\title{
Assess the Knowledge on Menopausal Self-care among Perimenopausal Women
}

\author{
${ }^{1} \mathrm{~N}$ Anjaly, ${ }^{2}$ Lekha Viswanath, ${ }^{3} \mathrm{~T}$ Anju Philip
}

\begin{abstract}
Perimenopause which generally begins more than 5 years before the permanent cessation of menses, it is a time of transition characterized by unstable endocrine physiology and highly variable, unpredictable hormone profiles. The purpose of the study is to assess the knowledge on menopausal self-care among perimenopausal women in selected wards of Nayarambalam Panchayath, Ernakulam. Quantitative approach with descriptive survey design is used for the study. Sample consists of 120 perimenopausal women of 35 to 50 years, residing in selected wards of Nayarambalam Panchayath, Ernakulam. The knowledge regarding menopausal self-care is poor among $71 \%$ of perimenopausal women, average among $28 \%$ of perimenopausal women and $1 \%$ of them have good knowledge. Mean knowledge score is $8.04, \mathrm{SD}$ is 5.09 and maximum score is 30 . No significant association was found between knowledge and variables like age, educational status, family income and menopausal status. Perimenopausal women have inadequate knowledge on menopausal self-care. Findings of the study highlight the need of educational intervention for improving the knowledge of self-care among perimenopausal women.
\end{abstract}

Keywords: Knowledge on menopausal self-care, Perimenopausal women, Selected variables.

How to cite this article: Anjaly N, Viswanath L, Philip TA. Assess the Knowledge on Menopausal Self-care among Perimenopausal Women. J South Asian Feder Menopause Soc 2014;2(2):55-58.

\section{Source of support: Nil \\ Conflict of interest: None}

\section{INTRODUCTION}

The natural menopause is defined as the permanent cessation of menstruation resulting from the loss of ovarian follicular activity. Natural menopause is recog-

\footnotetext{
${ }^{1} \mathrm{MSc}$ Nursing Student (IInd Year), ${ }^{2}$ Associate Professor

${ }^{3}$ Assistant Professor

${ }^{1}$ Department of Obstetrics and Gynecological Nursing, Amrita College of Nursing, Amrita Viswavidyapeetham, Amrita Institute of Medical Sciences, Kochi, Kerala, India

${ }^{2,3}$ Department of Obstetrics and Gynecological Nursing, Amrita Institute of Medical Sciences, Amrita Viswavidyapeetham, Kochi Kerala, India
}

Corresponding Author: NAnjaly, MSc Nursing Student (IInd Year) Department of Obstetrics and Gynecological Nursing, Amrita College of Nursing, Amrita Viswavidyapeetham, Amrita Institute of Medical Sciences, Kochi, Kerala, India, e-mail: anjalynarayanan5@gmail.com nized to have occurred after 12 consecutive months of amenorrhea. Perimenopause is the period immediately prior to the menopause (when the endocrinological, biological and clinical features approaching menopause commences) and the first year after menopause. ${ }^{1}$ According to North American Menopause Society, menopause can occur naturally (spontaneously)—on average around 51 years of age. Average age of menopause is 47.5 years in Indian women with an average life expectancy of 71 years. Mean age at menopause ranges in Indian women from 40.32 to 48.84 years. $^{2}$

Kapur P et al ${ }^{3}$ conducted a study on measuring climacteric symptoms and age at natural menopause in an Indian population using the Greene Climacteric Scale in Uttarakhand. According to the study age of menopause was $45.02 \pm 4.35$ years. According to Dasgupta $D^{4}$ study on menopausal problems among rural and urban women from eastern India found that the age of menopause is $46.14 \pm 4.47$ years.

Evidence show that women attain menopause at an earlier age compared to what it was before. Since, life expectancy has increased women have to live in menopausal years for a prolonged period of time. Hence, they are exposed to the risk of menopausal problems and health hazards.

Borker SA et al ${ }^{5}$ conducted a community based cross sectional study to find the prevalence of menopausal symptoms and perceptions regarding menopause among menopausal women of Kerala in 2013. The study was conducted among 106 postmenopausal women. The mean age of attaining menopause was 48.26 years. Prevalence of symptoms among women were emotional problems like crying spells, depression, irritability $(90.7 \%)$, headache $(72.9 \%)$, lethargy $(65.4 \%)$, dysuria $(58.9 \%)$, forgetfulness (57\%), musculoskeletal problems like joint pain, muscle pain (53.3\%), sexual problems like decreased libido, dyspareunia $(31.8 \%)$, genital problems like itching, vaginal dryness $(9.3 \%)$, and changes in voice $8.4 \%$. Only $22.4 \%$ of women knew the correct cause of menopause.

A study of Suguna $\mathrm{S}$ et $\mathrm{al}^{6}$ on menopausal transition and cardiovascular risk factors in urban Indian women in 2006 shows that postmenopausal women are at high risk for developing cardiovascular disease. Sharma S et $\mathrm{al}^{7}$ conducted a research on postmenopausal women's risk of developing osteoporosis found that mean age of 
osteopenia is 49.83 years and osteoporosis is 56.37 years and found that postmenopausal women is at risk of developing osteoporosis.

In India, the number of menopausal women is about 43 million. ${ }^{1}$ Women usually perceive themselves to be healthy even if they are not healthy. They are usually involved in taking care of family and given second priority to them. A study conducted by Pinto $\mathrm{ME}^{8}$ on knowledge and attitude regarding menopause among rural urban married women in Mangalore, sample size consisted of 100 married women aged between 40 to 50 years. Results show that majority of the women in rural area $(78 \%)$ had average knowledge on menopause and most of the women in urban area (62\%) had satisfactory knowledge regarding menopause. Most of the women in rural area (84\%) and urban area (98\%) had favorable attitude toward menopause, there was significant difference between knowledge scores and attitude scores of rural and urban married women regarding menopause.

Since perimenopause has lots of problem of physical and mental nature, the demand of life is much more. They need how to cope up with problems and demands. Many changes both physiological and psychological take place in women's body at this time. It is important that such woman receive help, advice and freely available information which can contribute toward making the years following menopause as rewarding, fulfilling and purposeful. The purpose of the present study is to identify knowledge on menopausal self-care, so as to help the healthcare provider with necessary data to device interventions specific to the needs of perimenopausal women. It will also help to identify the specific areas of self care deficit.

\section{MATERIALS AND METHODS}

Quantitative research with descriptive survey design is used for the present study. Research setting of the present study is Nayarambalam Grama Panchayath. This panchayath is adopted by Amrita Institute of Medical Sciences as a community health training center. The total population of Nayarambalam Panchayath is about 26,000 and consists of 16 wards. Sampling technique used is cluster sampling. Out of 16 wards 13 and 14 wards were selected using lottery method. The sample size consisted of 120 perimenopausal women between the age group of 35 to 50 years. The data were collected by semi structured questionnaire developed by the investigator. The knowledge questionnaire has 30 items. One mark is awarded for each right answer and zero for the wrong answer. No negative mark is given. The content validity of the tool is 0.9 and reliability is 0.69 .
The data collected was analyzed by descriptive statistics and inferential statistics.

\section{OBSERVATIONS AND RESULTS}

The data collected for the study was tabulated, analyzed and interpreted using descriptive and inferential statistics with the help of SPSS package.

The findings are presented under the following sections:

Section I: Sample characteristics

Section II: Knowledge on menopausal self care

Section III: Association of knowledge with selected demographic variables.

\section{Section I: Sample Characteristics}

Most of the subjects (37\%) belong to the age group between 35 and 40 years. Among 120 samples, 48\% attained menopause, $33 \%$ of them have diabetes, $25 \%$ of them have hypertension and $8 \%$ of them have osteoporosis.

The common change in menstrual pattern experienced by the perimenopausal women is irregular bleeding $(50 \%)$.

Most prevalent symptoms of menopause were, back pain $(66.6 \%)$, body pain $(37.5 \%), 33.3 \%$ have hot flushes, $29.1 \%$ have head ache, 25\% have vaginal dryness, $15 \%$ have urinary problems, $10 \%$ of them have sexual problems and $8.3 \%$ have dyspareunia (Graph 1).

\section{Section II: Knowledge on Menopausal Self-care}

Maximum score for the knowledge questionnaire is 30 . Knowledge level is graded in to; Below average knowledge (less than 10 marks), Average knowledge (11-20 marks) marks, above average knowledge (Above 21 marks).

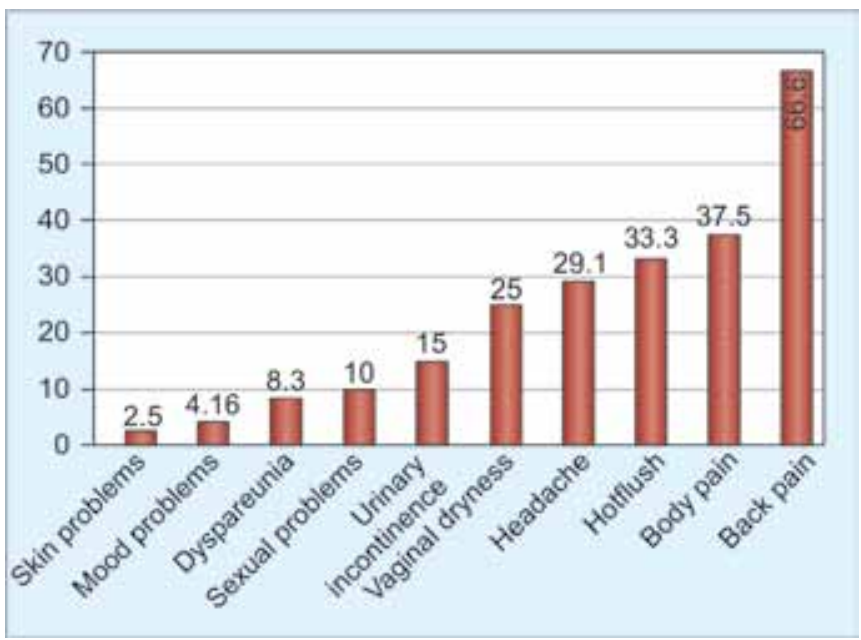

Graph 1: Menopausal symptoms experienced by perimenopausal women 


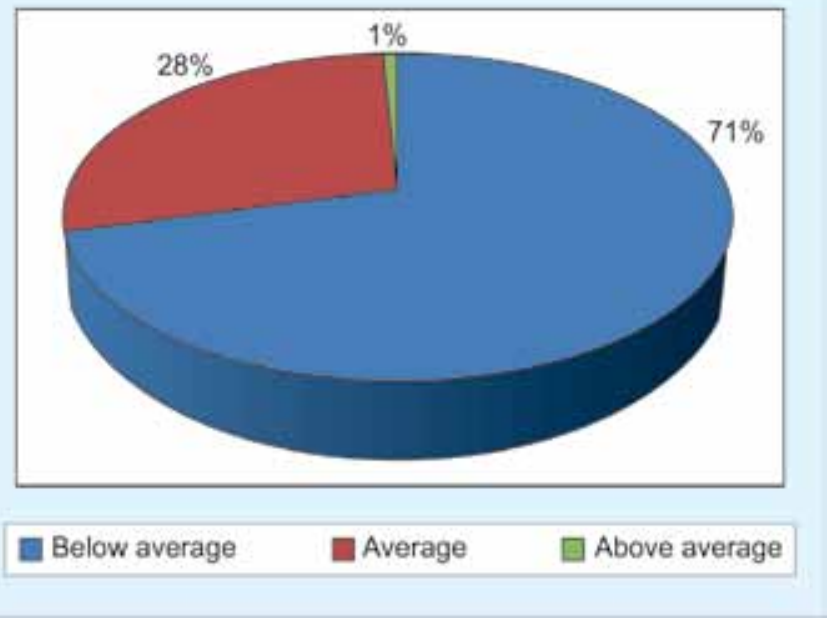

Graph 2: Pie diagram showing knowledge on menopausal self-care among perimenopausal women

Table 1: Mean score of knowledge in different areas of menopausal self-care

\begin{tabular}{llll}
\hline $\begin{array}{l}\text { Specific areas of } \\
\text { awareness level }\end{array}$ & $\begin{array}{l}\text { Maximum } \\
\text { score }\end{array}$ & $\begin{array}{l}\text { Mean score } \\
\text { and standard } \\
\text { deviation }\end{array}$ & $\begin{array}{l}\text { Mean } \\
\text { score } \\
(\%)\end{array}$ \\
\hline $\begin{array}{l}\text { 1. General aspects } \\
\text { of menopause }\end{array}$ & 5 & $0.88 \pm 0.80$ & 17.6 \\
$\begin{array}{l}\text { 2. Menopausal } \\
\text { symptoms and } \\
\text { management }\end{array}$ & 16 & $4.54 \pm 2.82$ & 28.3 \\
$\begin{array}{l}\text { Vasomotor } \\
\quad \text { symptoms }\end{array}$ & 5 & $2 \pm 0.95$ & 19 \\
- Genitourinary & 3 & $0.89 \pm 0.134$ & 29.6 \\
$\quad$ symptoms & & $1.16 \pm 0.98$ & 38.6 \\
- Psychological & 3 & $2.17 \pm 1.47$ & 24.1 \\
$\quad$ symptoms & & & \\
3. Long-term risk of \\
menopause and \\
prevention
\end{tabular}

${ }^{*}$ Certain items in the questionnaire are included under more than one specific area; Knowledge scores are less than $80 \%$ in all the specific areas. Knowledge score is less than $30 \%$ in general aspects of menopause, vasomotor symptoms, cancer and exercise

Graph 2 shows that the knowledge regarding menopausal self-care is poor among $71 \%$ of perimenopausal women, average among $28 \%$ of perimenopausal women and $1 \%$ of them have above average knowledge. Mean score is 8.04 and $\mathrm{SD}$ is $8.04 \pm 5.09$. The score ranged from 1 to 20 .

Score in different specific areas of knowledge on menopause is given in Table 1 .

\section{Section III: Association of Knowledge with Selected Demographic Variables}

No significant association found between educational status, family income and menopause attained to the knowledge level of the perimenopausal women $(p<0.05)$.

\section{DISCUSSION}

Knowledge regarding menopausal self-care is poor among $71 \%$ of perimenopausal women, average among $28 \%$ of perimenopausal women and $1 \%$ of them have good knowledge. Mean score and standard deviation of knowledge score is $8.04 \pm 5.09$ respectively with maximum score 30 . Mean score in all the specific areas of menopausal self-care was at less than $50 \%$ and they scored less than $25 \%$ knowledge in general aspects of menopause $(17.6 \%)$, vasomotor symptoms $(19 \%)$, Long term risk of menopause (24.1\%) and exercise (25\%).

A similar study conducted by James $\mathrm{J},{ }^{9}$ to evaluate the effectiveness of the structured teaching program on knowledge regarding menopausal problems and its remedial measures among middle aged women in selected rural areas, Bangalore. The results shows that pretest knowledge was inadequate in $71.7 \%$ of women, $28.3 \%$ of them have moderate knowledge and none of them have good knowledge on menopausal problems and its remedial measures. The subjects are having least knowledge in different areas of menopause like, general information on menopause (33.4\%), menopausal problems and remedial measures (41.9\%).

While comparing it shows that the results are more or less consistent in nature.

In the present study perimenopausal women is having, $37.3 \%$ of knowledge regarding osteoporosis with a mean score of $2.21 \pm 1.24$.

K Pande, Sonali Pande et $\mathrm{a}{ }^{10}$ conducted a study on knowledge about osteoporosis in learned Indian women. A total of 73 female staff members (average age 44.7 years) of a teaching institute taken as sample for the study. The mean \pm SD of total score for the sample was $4.1 \pm 4$.1. The highest and the lowest score were 15 and -8 respectively. Findings of the study are consistent with available literature. Healthcare providers need to emphasize the areas of insufficient knowledge while giving health education to prevent and manage menopausal symptoms and longterm risks. These study results conclude that women are having poor knowledge regarding osteoporosis and its preventive management. Women are having less than $50 \%$ knowledge in all specific areas of menopausal selfcare. It shows that women need to be get advises and help during their perimenopausal period itself because menopause is inevitable in every women's life. Healthcare providers should early identify the health hazards due 
to the menopause and measures should be done to minimize or eliminate the problems such as heart diseases, cancer and osteoporosis.

There is no significant association between age, educational status, family income and menopause attained to the knowledge level of the perimenopausal women.

Veigas et $\mathrm{al}^{11}$ conducted a study on knowledge and practice of post menopausal women on health maintenance in a selected rural community of Mangalore, Karnataka. Eighty postmenopausal rural women were selected randomly. There was no association observed between knowledge score and selected demographic variables such as age, education and family income.

\section{CONCLUSION}

Majority of the women experience menopausal problems in their life. So the healthcare providers should be knowledgeable regarding the menopausal problems, its health hazards as well as remedial measures. The administrator can impart various health education programs to the women attending hospital in various settings, and it can be replicated through the students. Menopause clinics can be established in order to get special care to the women in their menopause transition period.

\section{ACKNOWLEDGMENT}

I express my sincere gratitude to Professor Leelamani, HOD of community medicine department, AIMS, Kochi and Dr Aswathy, Professor Department of community medicine, AIMS, Kochi for their support throughout the study. I am thankful to Dr Sobha S Nair, Dr Smitha Joy for their suggestions and criticism for the study. And I am thankful to Nayarabalam Panchayath Authority for granting me permission to conduct the study in the Nayarambalam Panchayath.

\section{REFERENCES}

1. WHO technical report series, research on menopause 1980.

2. Third Consensus meeting of IMS, Indian Menopause Society, 2008. Available at: http://www.jmidlifehealth.org/ downloadpdf.asp?

3. Kapur P, et al. Measuring climacteric symptoms and age at natural menopause in an Indian population using the Greene Climacteric Scale. Menopause 2009 Mar-Apr;16(2):378-384.

4. Dasagupta D. Menopausal problems among rural and urban women from Eastern India. J Social Behavioral Health Sciences 2009;3(1):20-33.

5. Borker SA, Venugopalan PP, Bhat SN. Study of menopausal symptoms, and perceptions about menopause among women at a rural community in Kerala. J Mid-life Health [serialonline] 2013 [cited 2014 Mar 18];4:1827. Available at: http://www.jmidlifehealth.org/text.asp? 2013/4/3/ 182/118997.

6. Suguna S. Menopausal transition and cardiovascular risk factors in urban Indian women, 2006: Available at: http:// hdl.handle.net/123456789/1753.

7. Sharma S, et al. Effectiveness risk assessment tool for osteoporosis in Indian menopausal female J Midlife Health. 2010 Jul-Dec;1(2):79-85. Available at: URL: http://www.ncbi.nlm. nih.gov/pmc/articles/PMC3122502/.

8. Pinto M. Knowledge and attitude regarding menopause among rural urban married women in Mangalore. Available at: www.jaypeejournals.com/eJournals/ShowText.aspx?ID

9. James J. Evaluate the effectiveness of the structured teaching program on knowledge regarding menopausal problems and its remedial measures among middle aged women in selected rural areas, Bangalore.

10. Pande K, et al. A study on knowledge about osteoporosis in learned Indian women. JAPI 2005 May;53. Available at: www. japi.org

11. Veigas, et al. A study on knowledge and practice of post menopausal women on health maintenance in a selected rural community of Mangalore, Karnataka, Advances in Life Science and Technology ISSN 2224-7181 (Paper) ISSN 2225-062X (Online), 2014:17. 